\title{
Determinación de los parámetros óptimos en el procesamiento de la acara (Carica candicaens Gray) en almíbar
}

\author{
Determination of the optimal parameters in the processing of acara (Carica candicaens Gray) in syrup \\ Determinação dos parâmetros ótimos no processamento de acará (Carica candicaens Gray) em xarope
}

\author{
Kamiggia Jhonal Huaylla Ramirez \\ huayllark1@gmail.com \\ https://orcid.org/0000-0002-1484-3987
}

Universidad Nacional de Huancavelica, Huancavelica, Perú

\author{
Alfonso Ruiz Rodríguez \\ alfonso.ruiz@unh.edu.pe \\ https://orcid.org/0000-0002-0852-5878
}

Universidad Nacional de Huancavelica, Huancavelica, Perú

\author{
Franklin Ore Areche \\ franklin.agroin@gmail.com \\ https://orcid.org/0000-0002-7168-1742 \\ Universidad Nacional de Huancavelica, Huancavelica, Perú
}

\section{RESUMEN}

Perú es conocido por tener una gran diversidad de frutas exóticas, entre ellas se encuentra la Carica candicaens Gray. La presentación de almíbar de acara como una alternativa de conservar los frutos e incentivar su consumo. El objetivo del estudio fue determinara los parámetros de elaboración del almíbar de acara, determinar la aceptabilidad y realizar el análisis microbiológico al almíbar de acara. Para la elaboración del se obtuvo el fruto de acara del distrito de Ticrapo, provincia de Castrovirreyna - Huancavelica; se realizaron 3 tratamientos, cada uno a diferentes temperaturas y tiempos. El análisis sensorial se realizó con 15 panelistas semi entrenados, teniendo como resultado para el color 3,83 de aceptación, para el aroma 3,81 de aceptación, para el sabor 3,80 de aceptación y la consistencia 3,86 de aceptación. Del análisis sensorial puede indicarse que existen diferencias significativas para cada atributo evaluado entre los 3 tratamientos. El tratamiento 2 (T2) ha sido escaldado a $60^{\circ} \mathrm{C}$ por 2 minutos. Para las características fisicoquímicas del almíbar se determinó el $\mathrm{pH}$ y el ${ }^{\circ}$ Brix, obteniendo 4,0 y 18 respectivamente, lo cual indica que el almíbar está dentro de los rangos y se encuentra en la clasificación de almíbar ligero. Se realizó el análisis químico proximal al fruto y al almíbar, no habiendo diferencias en ambos resultados. Para el análisis microbiológico se determinó las Bacterias Aerobios Mesófilos $<10 \mathrm{ufc} / \mathrm{g}$, Coliformes totales $<10 \mathrm{ufc} / \mathrm{g}$ y $\mathrm{E}$. Coli NMP $<3 \mathrm{NMP} / \mathrm{g}$, este resultado indica que el producto se encuentra apto para el consumo humano.

Palabras clave: almíbar; temperatura; tiempo; escaldado; Carica candicaens Gray

ABSTRACT

RESUMO

Peru is known for having a great diversity of exotic fruits, among them is the Carica candicaens Gray. The presentation of acara syrup as an alternative to preserve the fruits and encourage their consumption. The objective of the study was to determine the production parameters of acara syrup, determine the acceptability and perform the microbiological analysis of acara syrup. For the elaboration of the acara fruit was obtained from the district of Ticrapo, province of Castrovirreyna - Huancavelica; 3 treatments were carried out, each one at different temperatures and times. The sensory analysis was carried out with 15 semi-trained panelists, resulting in 3.83 acceptance for color, 3.81 acceptance for aroma, 3.80 acceptance flavor for taste, and 3.86 acceptance consistency. From the sensory analysis it can be indicated that there are significant differences for each attribute evaluated between the 3 treatments. Treatment 2 (T2) has been blanched at $60^{\circ} \mathrm{C}$ for 2 minutes. For the physicochemical characteristics of the syrup, the $\mathrm{pH}$ and ${ }^{\circ}$ Brix were determined, obtaining 4.0 and 18 respectively, which indicates that the syrup is within the ranges and is in the light syrup classification. The chemical analysis was carried out proximal to the fruit and the syrup, there being no differences in both results. For the microbiological analysis, Mesophilic Aerobic Bacteria $<10 \mathrm{cfu} / \mathrm{g}$, total Coliforms $<10 \mathrm{cfu} / \mathrm{g}$ and $\mathrm{E}$. Coli NMP $<3 \mathrm{NMP} / \mathrm{g}$ were determined, this result indicates that the product is suitable for human consumption.

Key words: syrup; temperature; weather; scalding; Carica candicaens Gray
O Peru é conhecido por ter uma grande diversidade de frutas exóticas, entre elas está a Carica candicaens Grey. A apresentação do xarope de acará como alternativa para conservar os frutos e estimular o seu consumo. O objetivo do estudo foi determinar os parâmetros de produção do xarope de acará, determinar a aceitabilidade e realizar a análise microbiológica do xarope de acará Para a elaboração do acará o fruto foi obtido no distrito de Ticrapo, província de Castrovirreyna - Huancavelica; Foram realizados 3 tratamentos, cada um em diferentes temperaturas e tempos. A análise sensorial foi realizada com 15 provadores semi-treinados, resultando em 3,83 aceitação para cor, 3,81 aceitação para aroma, 3,80 aceitação de sabor para sabor e 3,86 aceitação de consistência. A partir da análise sensorial pode-se indicar que existem diferenças significativas para cada atributo avaliado entre os 3 tratamentos. O tratamento 2 (T2) foi branqueado a $60^{\circ} \mathrm{C}$ por 2 minutos. Para as características físico-químicas do xarope, foram determinados o $\mathrm{pH} \mathrm{e}^{\circ} \mathrm{Brix}$, obtendose 4,0 e 18 respectivamente, o que indica que o xarope está dentro das faixas e está na classificação do xarope leve. A análise química foi realizada proximal ao fruto e ao xarope, não havendo diferenças em ambos os resultados. Para a análise microbiológica, foram determinadas bactérias aeróbias mesófilas $<10 \mathrm{cfu} / \mathrm{g}$, coliformes totais $<10 \mathrm{cfu}$ / ge E. Coli NMP <3 NMP / g, este resultado indica que o produto é adequado para consumo humano.

Palavras-chave: xarope; temperatura; clima; escaldamento; Carica candicaens Gray 


\section{INTRODUCCIÓN}

Actualmente la biodiversidad sigue sufriendo cambios dramáticos (1). Perú, como todos los países tropicales es depositario de una biodiversidad sorprendente, que incluye a una gran cantidad de recursos naturales; sin embargo, muchos de estos recursos son conocidos por grupos humanos locales o regionales y no han sido estudiados a profundidad ni divulgados adecuadamente (2).

Carica candicans Gray “mito", es un arbusto característico de los andes occidentales y los valles interandinos de Perú (3), el "mito" es una papaya silvestre que se encuentra en peligro de extinción (4), el cual pertenece al género Carica y se desarrolla en diferentes medios xerofíticos que van desde los 2000 a 3000 msnm $(5,6)$, se le usa como digestivo y el látex sirve para el tratamiento de la Leishmaniasis (Uta) y Bartonelosis (Verruga) (7-9,4).

El "mito" o "papaya silvestre" es un fruto de la familia Caricaceae especie Carica candicans Gray, conocido desde la época pre hispánica (10), es una planta xerofítica de alrededor de $3 \mathrm{~m}$ de altura, tallo grueso muy ramificado, de abundante látex de hojas grandes poco lobadas, siendo el haz de color verde oscuro y el envés revestida de un tomento blanco y caducifolia durante el verano (11) citado por (12). El fruto es una baya despuntada hacia el extremo opuesto del peciolo la pulpa de sabor agridulce, son consumidos en estado fresco por ser aromáticas y agradables al paladar (13), el fruto es caracterizado por un aroma agradable y textura gomosa que le hace ser normalmente consumido por los pobladores de la zona donde crecen los arbustos, así también los visitantes ocasionales (14).
Actualmente, la explotación es escasas en frutos oriundos peruanos y también no hay variedad en la información científica en la población de bajo arraigo y accesibilidad, sobre todo, si se trata del almíbar de su fruto, como es el caso del mito específicamente (6).

En la actualidad, el creciente interés por el consumo de una mayor gama de productos naturales con el fin de diversificar y potenciar nuestra alimentación va de la mano de la revalorización de productos autóctonos poco difundidos en el pasado. Ahora es común su promoción como alternativas y complementos a los productos que comúnmente se consumen (15).

El almíbar es una mezcla de agua con productos alimentarios que producen sabores dulces con características similares al azúcar o la miel (16). Las frutas en almíbares son técnicas de conservación de frutos enteros o troceados, que generalmente incrementa el valor calórico de las frutas; es ampliamente usado en productos de pastelería y repostería para complementar el sabor y viscosidad (17).

La tendencia al consumo de alimentos saludables ha impactado en la industria alimentaria en las últimas décadas, orientándola hacia el desarrollo de alimentos que proporcionen una nutrición balanceada con la ingesta optimizada de nutrientes. El consumo de productos naturales y saludables está aumentando, ya que los alimentos con procesos tradicionales se van relegando por su alto valor calórico (alto porcentaje de azúcar) y sabores exóticos (18).

La alimentación en el mundo, es un punto crítico para sostener el desarrollo del ser humano; naturalmente el hombre busca una 
vida mejor, una existencia más dichosa y prolongada, esta posibilidad tiene su respuesta en la prevención de enfermedades, de la vejez y de la misma muerte; muchos factores influyeron en los últimos años para que los hábitos en la vida cotidiana, fueran cambiando e impactando en distintos aspectos dentro de ellos la alimentación y la salud. Las exigencias laborales actuales, el stress, la crisis global, la seguridad, la limitación del tiempo disponible, son algunas de las causas que generan estos cambios, en ese contexto, la alimentación juega un rol preponderante provocando una tendencia a consumir comidas preparadas para ser consumidas en el hogar, alimentos para ser consumidos fuera de los restaurantes (19).

La mayoría de Jos productos alimenticios son perecederos, susceptible a deterioros físicos, químicos y biológicos, por cuanto existen formas inadecuadas de comercialización y transporte; frente a ello se plantea el uso racional y eficiente de las técnicas y metodologías de conservación de los alimentos como incentivar el cultivo de especies nativas adaptadas, tal como la cocona y la papaya, en su mejoramiento y promoción para el abastecimiento y consumo local, regional y nacional.

\section{MATERIALES Y MÉTODOS}

\section{Materia prima e insumos}

La muestra de los frutos de Carica candicans Gray se recolectaron del distrito de Ticrapo de la provincia de Castrovirreyna del departamento de Huancavelica.

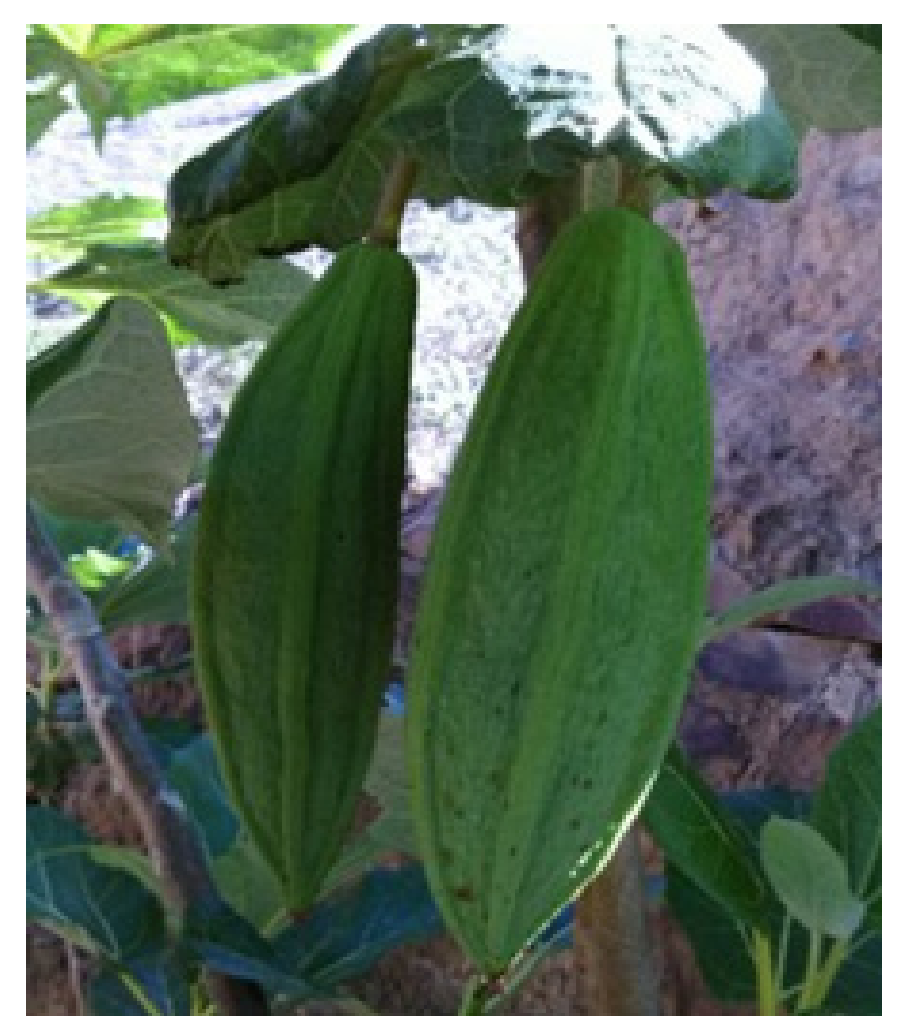

Figura 1. Fruto de acara. 
Los insumos como el Carboximetilcelulosa (CMC) y Ácido cítrico se adquirieron en la tienda "Químicos Porta" EIRL de la ciudad de Huancayo-Junín.

La azúcar blanca se adquirió en el mercado central del distrito y provincia de Castrovirreyna - Huancavelica.

\section{Elaboración de almíbar de Acara}

Recepción en el laboratorio. Al momento de la recepción se realizó el control de calidad del fruto de acara, con la finalidad de describir la situación inicial del fruto, dentro de estos controles esta el pesado, tamaño, y aspecto general, con la finalidad de describir la situación inicial de la materia prima.

Selección/clasificación. En esta etapa se realizó la eliminación de las muestras del fruto realizo para eliminar los frutos deteriorados, la clasificación se realizó para agrupar la fruta por: estado de madurez, forma, tamaño, color, etc.

Pesado. Se pesó para llevar a cabo los balances de masa y controlar los rendimientos.

Lavado/desinfectado. Los frutos de acara se lavaron para eliminar las partículas extrañas adheridas a la superficie y otros residuos del fruto, se realizó con agua potable, se realizó por inmersión. La desinfección se realizó con una solución de hipoclorito de sodio al $2 \%$ para eliminar todo el resto de microorganismos que estén adheridos a la superficie de la muestra.

Pelado. El pelado fue de forma manual con la ayuda de un cuchillo de acero inoxidable, donde se quitó cuidadosamente la cascara para evitar derrames de látex a la pulpa.

Escaldado: En esta se sometió la pulpa de acara en un baño de agua a tres diferentes temperaturas y tiempos: $50^{\circ} \mathrm{C}$ por 3 minutos, 60
${ }^{\circ} \mathrm{C}$ por 2 minutos y $70{ }^{\circ} \mathrm{C}$ por 1 minuto, con la finalidad de provocar la destrucción de enzimas (oxidativas) que pardea el producto, para fijar y conservar el color.

Preparado de jarabe: Se preparó la solución, donde se adicionó azúcar blanca, estabilizante (CMC) en un $0,25 \%$ y el $\mathrm{pH}$ se regulo a 3.3 .

Envasado: Los frutos escaldados de la acara en envaso en envases de vidrio de capacidad de $250 \mathrm{~g}$, se llenó la fruta escaldada y en seguida se llenó la solución del jarabe o almíbar a una temperatura de $85^{\circ} \mathrm{C}$. La cantidad de fruta en el envase es de $70 \%$ y de jarabe $30 \%$.

Sellado de envases: Los envases se sellaron manualmente inmediatamente de haberlo envasado.

Esterilización: Los envases sellados se sometieron a la autoclave por un tiempo de 15 minutos a una temperatura de $105^{\circ} \mathrm{C}$.

Enfriado: Después de retirar de la autoclave se dejó a enfriar a temperatura amiente.

Almacenamiento: Se realizo una limpieza superficial de los envases y se llevó a la refrigeradora.

\section{Métodos analíticos}

Evaluación sensorial. Se determino empleando 15 panelistas semi entrenados, donde se determinó los atributos de color, aroma y sabor; para lo cual se empleó una escala de 1 a 5, siendo 1 la menor calificación y 5 la máxima calificación.

pH. Se calculo utilizando el método 981.12 de la AOAC (1990), utilizando un pH Meter PH818 Smart Sensor.

Solidos solubles ( ${ }^{\circ}$ Brix). Se determinó utilizando el método 932.12 de la AOAC (1990). 
Humedad. AOAC 930.04 Cap 3, Pág 1 "20th Edition (2016).

Cenizas. AOAC 920.108 Cap 33, Pág 66 "19th Edition (2012).

Proteínas. AOAC 920.152 Cap 37, Pág 10 "20th Edition (2016)

Grasa. AOAC 930.09 Cap 3, Pág 24 “19th Edition (2012)

Fibra. AOAC 930.09 Cap 3, Pág 24 "19th Edition (2012)

Carbohidratos. Por diferencia MS-INN, Collazos, (1993)

Evaluación sensorial. Se determinó empleando 15 panelistas semi entrenados, donde se determinó los atributos de color, aroma y sabor; para lo cual se empleó una escala de 1 a 5 , siendo 1 la menor calificación y 5 la máxima calificación.

\section{Análisis estadístico de los datos}

Los datos obtenidos se expresaron en términos de media \pm desviación estándar. Los datos fueron analizados mediante un análisis de varianza-ANOVA con un nivel de confianza al $95 \%$ y una diferencia de medias Tukey empleando el software Statgraphics XVIl-X64.

\section{RESULTADOS Y DISCUSIÓN}

\section{Evaluación sensorial}

La evaluación sensorial se realizo para determinar el sabor, aroma, sabor y consistencia del almíbar de acara, donde resulto con mayor aceptabilidad el tratamiento 2 (T2), para el color obtuvo 3,83 de aceptación, para el aroma obtuvo 3,81 de aceptación, para el sabor obtuvo 3,80 de aceptación y para la consistencia obtuvo 3,86 de aceptación. El tratamiento 2 se escaldo a $60^{\circ} \mathrm{C}$ por 2 minutos.

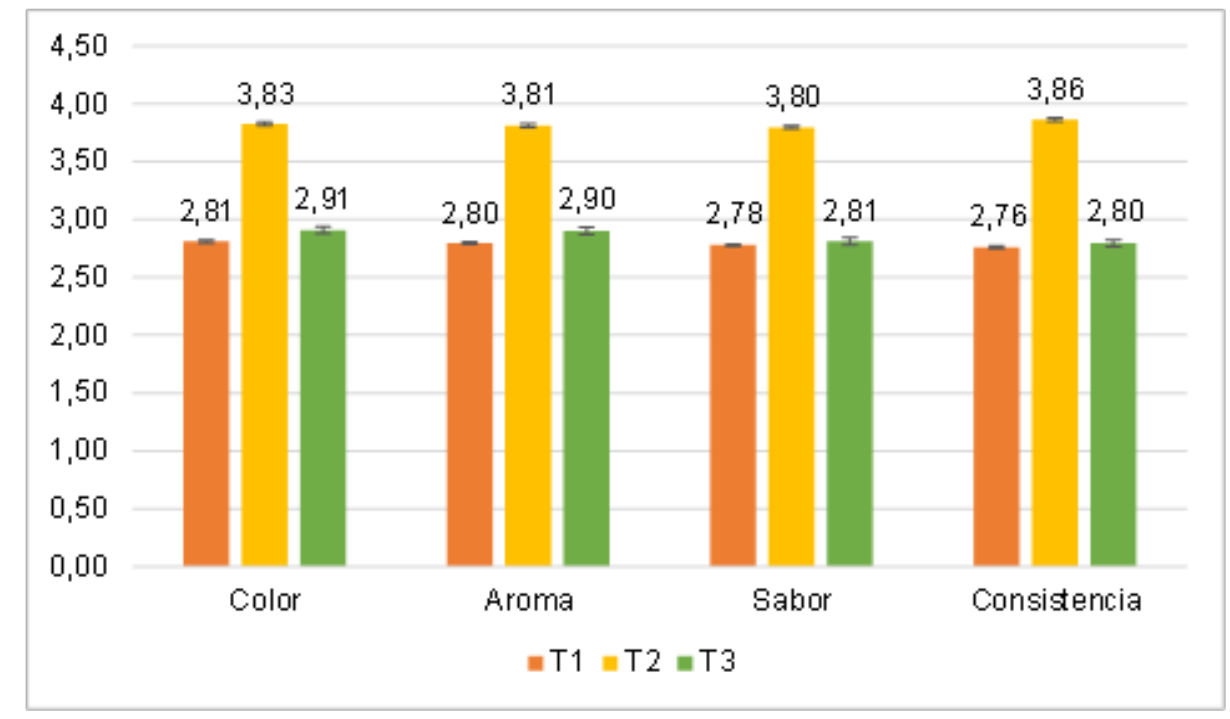

Figura 1. Resultados de la evaluación sensorial del almíbar de acara. 
Análisis fisicoquímicos del almíbar de acara

En la Tabla 1 se presentan los resultados del análisis fisicoquímico del almíbar de acara. El resultado del potencial de hidrógeno del almíbar de acara fue de 3,6. Los resultados en este estudio demostraron que el almíbar de acara clasifica como un almíbar ligero, ya que tiene $18{ }^{\circ}$ Brix. El almíbar de acara posee una tonalidad clara, lo cual influyo la pulpa del fruto.

Tabla 1. Análisis fisicoquímico del almíbar de acara.

\begin{tabular}{|c|c|}
\hline Análisis & Resultados \\
\hline $\mathrm{pH}$ & 4,0 \\
\hline${ }^{\circ}$ Brix & 18 \\
\hline
\end{tabular}

Determinación del análisis químico proximal del fruto de acara y del almíbar de acara

En la Tabla 2 se presenta los resultados del análisis químico proximal del fruto de acara y del almíbar de acara, que resulto aceptable en la evaluación sensorial, el cual ha sido escaldado a $60^{\circ} \mathrm{C}$ por 2 minutos.

Tabla 2. Análisis químico proximal del fruto de acara y del almíbar de acara.

\begin{tabular}{lcc}
\hline Análisis & Fruto de acara & Almíbar de acara \\
\hline Humedad & $91,57 \%$ & $91,20 \%$ \\
Ceniza & $0,62 \%$ & $0,42 \%$ \\
Proteína bruta & $1,08 \%$ & $1,09 \%$ \\
Grasa bruta & $0,02 \%$ & $0,84 \%$ \\
Fibra bruta & $0,70 \%$ & $0,61 \%$ \\
Carbohidratos totales & $5,99 \%$ & $7,37 \%$ \\
\hline
\end{tabular}

Análisis microbiológico de la acara en acara, que resulto aceptable en la evaluación almíbar sensorial, el cual ha sido escaldado a $60^{\circ} \mathrm{C}$ por

En la Tabla 3 se presenta los resultados 2 minutos. del análisis microbiológico del almíbar de

Tabla 3. Resultados del análisis microbiológico del almíbar de acara.

\begin{tabular}{cl}
\hline Análisis de laboratorio & Resultados \\
\hline Bacterias Aerobios Mesófilos & $<10 \mathrm{ufc} / \mathrm{g}$ \\
Coliformes totales & $<10 \mathrm{ufc} / \mathrm{g}$ \\
E. Coli NMP & $<3 \mathrm{NMP} / \mathrm{g}$ \\
\hline
\end{tabular}




\section{Discusión}

Se realizó al análisis químico proximal al fruto de acara, respecto a humedad $80,83 \%$, proteínas $91,57 \%$, ceniza $0,62 \%$, proteína bruta 1,08 , grasa bruta 0,02 , fibra bruta $0,70 \%$ y carbohidratos totales $5,99 \%$, expresado en base húmeda, estos datos son diferentes a los que obtuvo (12), esta variación podría ser a la procedencia del fruto.

El tratamiento con mayor aceptabilidad presentó un $\mathrm{pH}$ de 4,0. La acara contiene un $\mathrm{pH}$ de 5,90 el cual pudo aumentar el pH del producto final (20). Los análisis de potencial de hidrógeno según las normas mexicanas para el almíbar de duraznos con un $\mathrm{pH}$ mínimo de 3.5 y un máximo de 4.2, por lo que los resultados obtenidos en este estudio cumplieron con dichas especificaciones.

Según el Codex Alimentarius (21) el valor en 'Brix un almíbar podría clasificarse en: almíbar muy ligero $\left(10\right.$ y $\left.14^{\circ}\right)$, almíbar ligero $\left(14\right.$ y $\left.18^{\circ}\right)$, almíbar concentrado $\left(18\right.$ y $\left.22^{\circ}\right)$ y el almíbar muy concentrado (más de $22^{\circ}$ ), por lo cual el almíbar de acara está en la clasificación de almíbar ligero. Los resultados pudieron estar influenciados principalmente por los ${ }^{\circ}$ Brix de la acara, ya que es un fruto de bajo ${ }^{\circ}$ Brix.

Transcurrido el tiempo de estabilización (14 días) se procedió con la evaluación sensorial por 15 panelistas semi entrenada. Con respecto a los mayores puntajes fueron dados para el tratamiento 2 (T2), el cual obtuvo puntajes de 3,83 para el color; 3,81 para el aroma; 3,80 para el sabor y 3,86 para la consistencia; lo que pudieron representar alguna diferencia estadística $(p<0,05)$ atribuible a la prueba de rangos múltiples de Duncan. Por lo general las variaciones no tuvieron una mayor significación entre los atributos; cabe destacar que si existe diferencias significativas entre los tratamientos.

A través de la vista se pueden percibir varias propiedades sensoriales, de la cuales tenemos apariencia como un factor muy importante, ya que determina que tan apetecible es el producto. Mediante esta propiedad se puede percibir si un alimento puede tener un daño físico o químico, determinando a simple vista si el producto vale la pena o no consumirlo (22).

Los resultados microbiológicos del almíbar de acara, no presentan ningún grado de contaminación, se puede decir que es un alimento seguro, no hay presencia de bacterias aerobio mesófilos, coliformes totales y E. coli, esto indica que están aptos para su consumo (23).

\section{CONCLUSIONES}

Se determinaros los parámetros óptimos en el procesamiento de acara en almíbar, el cual fue de $60{ }^{\circ} \mathrm{C}$ de escaldado por 2 minutos, estos parámetros de determinaron mediante una evaluación sensorial al almíbar, donde resulto el tratamiento 2 (T2).

Se realizo la evaluación sensorial a los 3 tratamientos $(\mathrm{T} 1, \mathrm{~T} 2, \mathrm{y} \mathrm{T} 3)$ con 15 panelistas semi entrenados, donde resulto con mayor puntaje el tratamiento 2 (T2), para el color obtuvo 3,83 de aceptación, para el aroma obtuvo 3,81 de aceptación, para el sabor obtuvo 3,80 de aceptación y para la consistencia obtuvo 3,86 de aceptación.

El producto aceptable no presento bacterias aerobio mesófilos, coliformes totales y E. coli, lo cual indica que es apto para su consumo. 


\section{AGRADECIMIENTOS}

A la Universidad Nacional de Huancavelica que mediante el Vicerrectorado de Investigación y el PROGRAMA 0066-2017, cofinancio para el desarrollo de la presente investigación.

\section{REFERENCIAS BIBLIOGRÁFICAS}

1. Juárez A, Ayasta J, Aguirre R, Rodríguez E. La Oscurana (Cajamarca), un bosque relicto más para conservar en las vertientes occidentales andinas del norte dPerú. Revista Peruana de Biología, 12(2), 289-298. 2005; Recuperado en 09 de abril de 2021, de http://www.scielo.org. pe/scielo.php?script=sci_arttext\&pid=S172799332005000200012\&lng=es\&tlng=es

2. Sagástegui A, Rodrígues E, Arroyo S. Plan-tas promisorias: El mito o papaya silvestre. Innova Norte 1(1): 109-119. 2007.

3. Mendoza A. Biodiversidad y sustentabilidad de las ciudades costeras: necesidad de mantener áreas naturales de vida silvestre en la ciudad. Biologist (Lima) 4: 4-5. 2006.

4. Gutiérrez A, Nolasco O, Santa Cruz C. Purificación y caracterización preliminar de proteasas del látex de Vasconcellea candicans (A. Gray) A. DC (Mito). Scientia Agropecuaria, 2017; 8(1), 7-17. https://dx.doi.org/10.17268/sci. agropecu.2017.01.01

5. Sturtevant, E. Sturtevant's Notes on Edible Plant. Hendrick, U., P., Ed; J, B, Lyon Co: Albany, NY, 142- 143. 1919.

6. Mendoza G. Caracterización y cuantificación del comportamiento reológico de la pulpa de mito (Carica Candicans Gray). (Tesis de pregrado, Universidad Nacional Mayor de San Marcos, Facultad de Química e Ingeniería Química, Escuela Profesional de Ingeniería Agroindustrial). Repositorio institucional Cybertesis UNMSM. 2019.

7. Soukup J. Vocabulario de los Nombres Vulgares de la Flora Peruana. Edit. Salesiana S.A. Lima, Perú. 1970.
8. Brack A. Diccionario enciclopédico de plantas útiles del Perú. Descripción física. Lima, Perú. 1999; 556 pp.

9. De Feo, V, De Simone F, Arroyo GA, Senatore F. Carica candicans Gray (mito), an alimentary resource from Peruvian flora. Journal of Agricultural and Food Chemistry 1999, 47: 36823684.

10. Franco P. Estudio poblacional de Carica candicans (Papaya silvestre) en Lomas de Morro Sama y Lomas de Tacahuay. 2013; Tacna noviembre. $45 \mathrm{p}$.

11. Ferreyra R. Comunidades vegetales de algunas lomas costeras. Estación Experimental Agrícola. 1954; Boletín 53, 11-13.

12. Silva A, Honorio Z. Contenido de nutrientes de Carica candicans Gray "mito" fruto silvestre del departamento de Ancash, Perú. Artículo breve, Infinitum (Huacho). Universidad nacional José Faustino Sánchez Carrión. Huacho - Perú. 2015; 5(2)

13. El Peruano. Normas legales de Agricultura. Aprueban categorización de especies Amenazadas de Flora Silvestre. Decreto Supremo N 043-2006-AG. 2006, julio 16.

14. Uphof J. Th, Dictionary of Economic Plants; Verlag von J, Cramer: New York, 107. 1968.

15. Belli V. Estudio etnobotánico y morfológico de "mito" Vasconcellea candicans con énfasis en plántulas. Tesis para optar el título de Ingeniero Forestal. Universidad Nacional Agraria La Molina. Lima - Perú. 2018.

16. FAO (Food and Agriculture organization of the United Nations). Directrices del Codex sobre los líquidos de cobertura para las frutas en conserva CAC/GL51-2013. 2013.

17. Polo $D$, Sastre M. Aprovisionamiento interno en pastelería. HOTRO109. Frutas en almíbar. 2014; Ic Editorial. ISBN: 978-84-16109-09-8.

18. Club Darwin. Las 6 mega tendencias en alimentos. 2010; (en línea), (consultado 2021 abril 09). http://www.clubdarwin.net/seccion/ ingredientes/las-6-mega-tendencias-enalimentos 
19. Ida del Greco N. Estudio sobre tendencias de consumo de alimentos - Datos relevantes para la toma de decisiones en la. Lima - Ministerio de salud. 2010.

20. HenaoH,GiraldoG, MarínZ.Estabilización del Aloe vera (Aloe barbadensis Miller) empleando métodos combinados. Colombia. Universidad del Quindío. 2016; http://iicta.bogota.unal.edu. co/wp-content/uploads/2017/02/533C094.pd

21. Codex Alimentarius. Programa conjunto FAO/oms sobre normas alimentarias. Londres. Codex Alimentarius. 2000 (consultado 2021 abril 10). http://www.fao.org/tempref/codex/ Meetings/CCS/ccs7/S00_03s.pdf
22. Cordero G. Aplicación del análisis sensorial de los alimentos en la cocina y en la industria alimentaria. España. Universidad Pablo de Olavide. 19. 2013; https://www.researchgate. net/publication/262561546

23. Arapa F. Obtención de un almíbar a base de piña (Ananascomosus) con lactosuero. Perú. UNA-PUNO. 2012; http:// repositorio.unap.edu.pe/bitstream/handle/ UNAP/3402/Arapa_Fernandez_Fredy_Hernan. pdf?sequence $=5$ \&isAllowed $=y$ 